\title{
Daytime Sleepiness Among Young Adult Omani Car Drivers
}

"Mohammed A. Al-Abri, ${ }^{1}$ Samir Al-Adawi, ${ }^{2}$ Ibrahim Al-Abri, ${ }^{1}$ Faisal Al-Abri, ${ }^{1}$ Atsu Dorvlo, ${ }^{3}$ Ronald Wesonga, ${ }^{4}$ Sanjay Jaju ${ }^{5}$

$$
\text { النعاس النهاري بين الشباب البالغين سائقي المركبات في عمان }
$$

محمد عبد الله العبري، سمير العدوي، إبراهيم العبري، فيصل العبري، أتسو دورثلو، رونالد وسونغا، سانجاي هاجِو

ABSTRACT: Objectives: Sleepiness and fatigue play significant roles in exacerbating the occurrence of car crashes. However, there is a dearth of studies examining the prevalence of sleepiness while driving among Omanis. This study aimed to determine the proportion of young Omani adults who confess to daytime sleepiness while driving and to investigate associations between gender, daytime sleepiness and risk of obstructive sleep apnoea syndrome (OSAS). Methods: This cross-sectional study took place at the Sultan Qaboos University Hospital, Muscat, Oman, between May and July 2014 and included 600 young adult Omani non-commercial drivers. The Berlin Questionnaire and Epworth Sleepiness Scale (ESS) were distributed among the participants, along with additional questions about their sleeping habits. Associations between daytime sleepiness while driving and nocturnal sleep duration, risk of OSAS and gender were determined. Results: A total of 492 private vehicle drivers took part in the study (response rate: 82\%), of which 50.4\% were male. Overall, 124 Omanis (25.2\%) reported experiencing daytime sleepiness while driving at least once per month. There was a significant association between nocturnal sleep duration of $<6$ hours and sleepiness while driving $(P=0.042)$. Female participants were significantly more likely to score $>10$ on the ESS, indicating a greater propensity for daytime sleepiness $(P=0.006)$. However, male drivers were significantly more likely to report sleepiness while driving $(P=0.001)$. Conclusion: Sleepiness while driving was common among young male drivers in Oman and might be due to nocturnal sleep deprivation. Further studies are needed so that preventative measures can be developed.

Keywords: Motor Vehicles; Traffic Accidents; Sleep; Fatigue; Obstructive Sleep Apnea Syndrome; Oman.

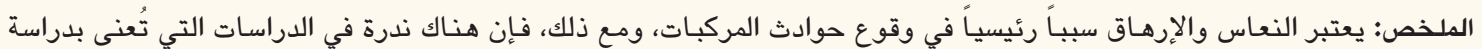

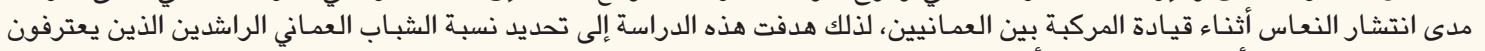

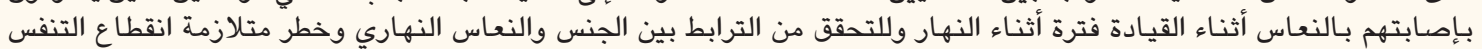

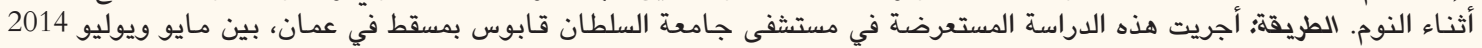

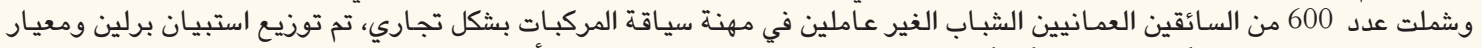

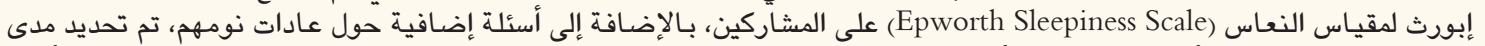

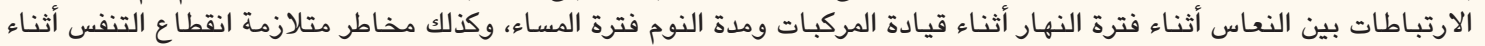

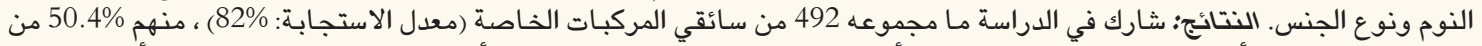

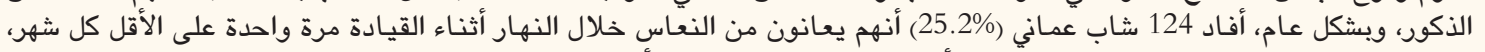

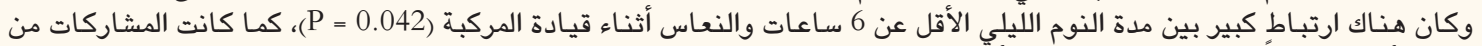

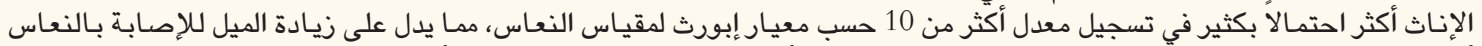

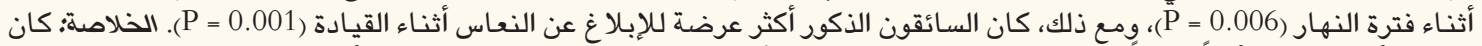

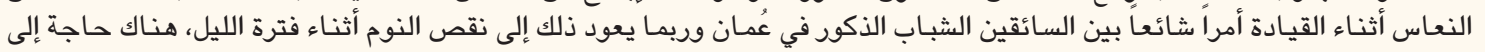

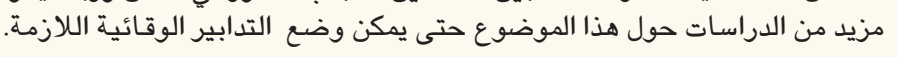

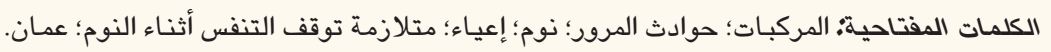

\section{AdvanCeS IN KNOWLEDGE}

To the best of the authors' knowledge, this study is the first to illustrate the prevalence of sleepiness while driving among young adult Omanis. These findings may be of use in legislative and educational measures for road traffic safety and the prevention of motor vehicle crashes.

\section{Application to Patient Care}

Sleepiness while driving can result in significant morbidity and mortality. As such, the results of this study may encourage physicians to refer sleepy drivers for further tests and early medical intervention. 
S LEEPINESS AND FATIGUE CAN DECREASE MENTAL alertness and increase the likelihood of errors and unintentional injuries among children, adolescents and adults., ${ }^{1,2}$ In particular, fatigue and daytime sleepiness have been shown to impair cognitive function while driving, which results in a higher risk of road traffic crashes. ${ }^{3}$ Extended work shifts can also disrupt the sleep-wake cycle and therefore heighten the risk of occupational injuries and motor vehicle crashes. ${ }^{4}$ In the UK, it is estimated that daytime sleepiness causes approximately $16 \%$ and $20 \%$ of all car crashes and those occurring on motorways, respectively. ${ }^{5}$

Nocturnal sleep deprivation and poor sleep hygiene are well-known causes of daytime sleepiness and tiredness, particularly among younger individuals. ${ }^{6,7}$ In addition to lack of sleep, there is evidence to suggest that sleep disorders such as obstructive sleep apnoea syndrome (OSAS) can trigger excessive daytime sleepiness. ${ }^{8}$ As such, patients with OSAS are at a 1.3-7-fold greater risk of having car crashes than the general population. ${ }^{8,9}$

Car crashes are one of the most common causes of mortality and morbidity among young people in Oman, a country of approximately 4.5 million individuals. ${ }^{10,11}$ In a review of epidemiological studies available in the literature, the prevalence of excessive daytime sleepiness ranged between 4-20.6\%, depending on the methods and definitions used. ${ }^{12}$ However, no studies have yet been conducted in Oman to determine the prevalence of daytime sleepiness among young adult drivers. This study therefore aimed to determine the proportion of young Omani drivers who confess to daytime sleepiness and to study the association of certain key risk factors such as gender, OSAS, body mass index (BMI) and snoring

\section{Methods}

This cross-sectional study was conducted among 600 young adults visiting the Sultan Qaboos University Hospital in Muscat, Oman, between May and July 2014. A systematic sampling technique was used to select every fifth Omani bystander or patient's relative between 20-40 years old passing through the main entrance of the hospital during outpatient clinic opening hours. There were 10 subjects approached per day for a total of 200 participants per month. Only apparently healthy individuals who drove noncommercial vehicles were included in the study. Subjects working night-shifts and commercial drivers (e.g. truck or taxi drivers) were excluded. In order to ascertain the prevalence of daytime sleepiness among young adult Omani drivers, the necessary sample size was determined based on a hypothesis testing a single proportion, with an alpha value set at 0.05 and a power of $80 \%$. Based on the findings of an earlier study in which $23 \%$ of drivers initially reported driving impairment due to sleepiness, daytime sleepiness while driving was assumed to be $26 \%$ in the current study, leading to a total required sample size of 369 drivers. $^{3}$

Validated English or Arabic versions of the Epworth Sleepiness Scale (ESS) were distributed to the participants in order to determine daytime sleepiness. ${ }^{13,14}$ The ESS is scored on a 3-point Likert scale, with the total score ranging from 0-24; a propensity towards daytime sleepiness is indicated at scores of $>10 .{ }^{13}$ Subsequently, participants were requested to complete either an English or Arabic version of the 10-item Berlin Questionnaire (BQ) to determine various symptoms of OSAS, such as the presence of snoring (category 1), daytime somnolence (category 2) and hypertension and high BMI (category 3). ${ }^{15,16}$ Participants were classified as being at either high or low risk of OSAS based on their responses to individual items and their overall BQ scores in each category, with those who scored positive in two or more categories classified as high-risk. ${ }^{15}$ The psychometric properties of the Arabic versions of both the ESS and BQ tools have been found to be adequate in Arab populations. ${ }^{14,16}$ In addition, participants were asked specific questions to gauge their average nocturnal sleep duration and the occurrence of daytime sleepiness over the preceding month. The height and weight of all subjects was also measured to calculate their BMI.

Statistical analyses were performed using the Statistical Package for the Social Sciences (SPSS), Version 21.0 (IBM Corp., Armonk, New York, USA). Summary stat-

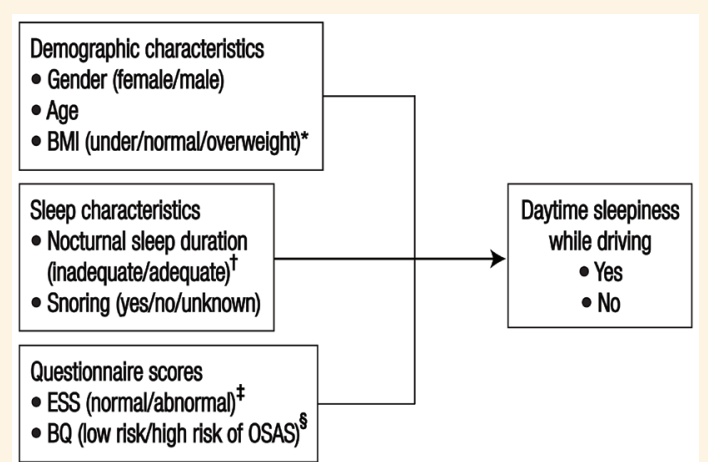

Figure 1: Diagram illustrating the various factors used in the current study to determine associations with daytime sleepiness while driving among young adult Omani drivers.

$B M I=$ body mass index $;$ ESS $=$ Epworth Sleepiness Scale; $B Q=B e$ rlin Questionnaire; OSAS = obstructive sleep apnoea syndrome.

*BMI category was classified as underweight $\left(<20 \mathrm{~kg} / \mathrm{m}^{2}\right)$, normal weight $\left(20-25 \mathrm{~kg} / \mathrm{m}^{2}\right)$ or overweight $\left(>25 \mathrm{~kg} / \mathrm{m}^{2}\right)$. ${ }^{+}$Nocturnal sleep duration was categorised as adequate ( $\geq 6$ hours) or inadequate $\left(<6\right.$ hours)..$^{17}{ }^{7}$ ESS scores were categorised as normal $(0-10)$ or abnormal (>10). ${ }^{\mathbb{B}} B Q$ scores were categorised as high risk of OSAS (positive scores in two or more categories) or low risk of OSAS (positive scores in one or zero categories). 
Table 1: Prevalence of daytime sleepiness and nocturnal sleep deprivation according to gender among young adult Omani drivers $(\mathrm{N}=492)$

\begin{tabular}{|c|c|c|c|}
\hline \multirow[t]{2}{*}{ Factor } & \multicolumn{2}{|c|}{ n (\%) } & \multirow{2}{*}{$\begin{array}{c}P \\
\text { value }\end{array}$} \\
\hline & $\begin{array}{l}\text { Male drivers } \\
\quad(\mathbf{n}=248)\end{array}$ & $\begin{array}{l}\text { Female drivers } \\
\quad(\mathrm{n}=244)\end{array}$ & \\
\hline $\begin{array}{l}\text { Mean age in } \\
\text { years } \pm S D\end{array}$ & $30.0 \pm 8.5$ & $32.5 \pm 5.0$ & $<0.001$ \\
\hline $\begin{array}{l}\text { Mean BMI in } \\
\mathrm{kg} / \mathrm{m}^{2} \pm \mathrm{SD}\end{array}$ & $25.6 \pm 4.0$ & $24.6 \pm 4.2$ & 0.007 \\
\hline \multicolumn{4}{|c|}{ Daytime sleepiness while driving } \\
\hline Yes & $83(33.5)$ & $44(18)$ & \multirow{2}{*}{0.001} \\
\hline No & $165(66.5)$ & $200(82)$ & \\
\hline \multicolumn{4}{|c|}{ Nocturnal sleep duration in hours } \\
\hline$<6$ & $157(63.3)$ & $147(60.2)$ & \multirow{2}{*}{0.485} \\
\hline$\geq 6$ & $91(36.7)$ & $97(39.8)$ & \\
\hline
\end{tabular}

istics and two sample t-tests were computed and $P$ values provided where appropriate. A Chi-squared test was used to determine associations between categorical variables such as age, gender, BMI, snoring, ESS scores, risk of OSAS and sleepiness while driving [Figure 1]. A cut-off time of 6 hours was deemed to indicate adequate nocturnal sleep, with anything under this deemed to constitute nocturnal sleep deprivation. ${ }^{17}$ The level of statistical significance was set at $P \leq 0.050(\alpha=0.05)$.

This study was approved by the Medical Research \& Ethics Committee of the College of Medicine \& Health Sciences, Sultan Qaboos University (\#MREC 963). Participants provided informed written consent prior to their enrolment in the study.

\section{Results}

A total of 492 drivers agreed to participate in this study (response rate: 82\%). Of these, 248 (50.4\%) were male and $244(49.6 \%)$ were female. The mean age of the male drivers was $30.0 \pm 8.5$ years and the mean age of the female drivers was $32.5 \pm 5.0$ years. The mean BMI was $25.6 \pm 4.0 \mathrm{~kg} / \mathrm{m}^{2}$ and $24.6 \pm 4.2 \mathrm{~kg} / \mathrm{m}^{2}$ for male and female drivers, respectively. There were significant differences noted in terms of age and BMI according to gender $(P<0.050$ each). Overall, 127 young drivers (25.8\%) had experienced daytime sleepiness while driving. Male drivers reported significantly greater daytime sleepiness compared to females $(33.5 \%$ versus $18 \% ; P=0.001$ ). However, no gender difference was noted in terms of average nocturnal sleep duration [Table 1].

There was a significant association between daytime sleepiness while driving and nocturnal sleep deprivation
Table 2: Risk factors associated with daytime sleepiness while driving among young adult Omani drivers $(\mathrm{N}=492)$

\begin{tabular}{|c|c|c|c|}
\hline \multirow[t]{2}{*}{ Risk factor } & \multicolumn{2}{|c|}{$\begin{array}{l}\text { Daytime sleepiness while driving, } \\
\text { n(\%) }\end{array}$} & \multirow[t]{2}{*}{$P$ value } \\
\hline & $\begin{array}{c}\text { Yes } \\
(\mathrm{n}=127)\end{array}$ & $\begin{array}{c}\text { No } \\
(n=365)\end{array}$ & \\
\hline \multicolumn{4}{|c|}{ Nocturnal sleep duration in hours } \\
\hline$<6$ & $88(69.3)$ & $216(59.2)$ & \multirow{2}{*}{0.041} \\
\hline$\geq 6$ & $39(30.7)$ & $149(40.8)$ & \\
\hline \multicolumn{4}{|c|}{$\mathrm{BMI}$ in $\mathrm{kg} / \mathrm{m}^{2}$} \\
\hline$<20$ & $5(3.9)$ & $10(2.7)$ & \multirow{3}{*}{0.009} \\
\hline $20-25$ & $47(37)$ & $193(52.9)$ & \\
\hline$>25$ & $75(59.1)$ & $162(44.4)$ & \\
\hline \multicolumn{4}{|l|}{ Snoring } \\
\hline No & $67(52.8)$ & $268(73.4)$ & \multirow{3}{*}{$<0.001$} \\
\hline Yes & $46(36.2)$ & $60(16.4)$ & \\
\hline Unknown & $14(11)$ & $37(10.1)$ & \\
\hline
\end{tabular}

$B M I=$ body mass index

Table 3: Associations between gender and Epworth Sleepiness Scale and Berlin Questionnaire scores among young adult Omani drivers $(\mathrm{N}=492)$

\begin{tabular}{llcl} 
Score & \multicolumn{2}{c}{ n(\%) } & Pvalue \\
& $\begin{array}{c}\text { Male drivers } \\
(\mathbf{n}=248)\end{array}$ & $\begin{array}{c}\text { Female drivers } \\
(\mathbf{n}=244)\end{array}$ & \\
ESS & $169(68.1)$ & $137(56.1)$ & \\
$0-10$ & $79(31.9)$ & $107(43.9)$ & \\
$>10$ & & & \\
BQ & $32(12.9)$ & $20(8.2)$ & 0.096 \\
High risk & $216(87.1)$ & $224(91.8)$ & \\
Low risk & &
\end{tabular}

ESS = Epworth Sleepiness Scale; $B Q=$ Berlin Questionnaire.

"Positive scores in two or more categories. ${ }^{\dagger}$ Positive scores in one or zero categories.

$(P=0.041)$, BMI $(P=0.009)$ and snoring $(P<0.001)$. Among those who reported sleepiness while driving, the majority had fewer than 6 hours of sleep per night (69.3\%) and were overweight (59.1\%). Furthermore, the proportion of those with daytime sleepiness was doubled among those who snored compared to those who did not snore (36.2\% versus $16.4 \%$ ) [Table 2]. Significantly more females than males were found to have a propensity towards daytime sleepiness as per their ESS scores (43.9\% versus $31.9 \% ; P=0.006)$. However, although more males than females were categorised as at high-risk of OSAS based on their BQ scores, this difference was not significant (12.9\% versus $8.2 \%$; $P=0.093)$ [Table 3]. 
Table 4: Associations between daytime sleepiness while driving and Epworth Sleepiness Scale and Berlin Questionnaire scores according to gender among young adult Omani drivers $(\mathrm{N}=492)$

\begin{tabular}{|c|c|c|c|c|}
\hline \multirow{2}{*}{\multicolumn{2}{|c|}{ Score }} & \multicolumn{2}{|c|}{$\begin{array}{l}\text { Daytime sleepiness } \\
\text { while driving, } \\
\text { n (\%) }\end{array}$} & \multirow[t]{2}{*}{$P$ value } \\
\hline & & $\begin{array}{c}\text { Yes } \\
(\mathbf{n}=127)\end{array}$ & $\begin{array}{c}\text { No } \\
(\mathbf{n}=365)\end{array}$ & \\
\hline \multirow{6}{*}{ 岕 } & Male & & & \multirow{4}{*}{0.108} \\
\hline & $0-10$ & 51 (61.4) & 118 (71.5) & \\
\hline & $>10$ & $32(38.6)$ & $47(28.5)$ & \\
\hline & Female & & & \\
\hline & $0-10$ & 17 (38.6) & $120(60)$ & \multirow{2}{*}{0.010} \\
\hline & $>10$ & 27 (61.4) & $80(40)$ & \\
\hline \multirow{6}{*}{$\underset{\infty}{\sigma}$} & Male & & & \\
\hline & High risk" & $19(22.9)$ & $13(7.9)$ & \multirow{2}{*}{0.001} \\
\hline & Low risk ${ }^{\dagger}$ & 64. (77.1) & $152(92.1)$ & \\
\hline & \multicolumn{3}{|l|}{ Female } & \\
\hline & High risk" & $8(18.2)$ & $12(6)$ & \multirow{2}{*}{0.014} \\
\hline & Low risk ${ }^{\dagger}$ & $36(81.8)$ & $188(94)$ & \\
\hline
\end{tabular}

ESS $=$ Epworth Sleepiness Scale; $B Q=$ Berlin Questionnaire. "Positive scores in two or more categories. ${ }^{+}$Positive scores in one or zero categories.

Overall, sleepiness while driving was significantly associated with ESS and BQ scores $(P=0.023$ and $<0.001$, respectively).

Female drivers who reported daytime sleepiness while driving had significantly higher ESS scores in comparison to those who did not report daytime sleepiness $(61.4 \%$ versus $38.6 \%$; $P=0.010)$. Moreover, in terms of BQ scores, there were significantly more women who reported daytime sleepiness at high risk of OSAS than at low risk ( $81.8 \%$ versus $18.2 \% ; P=0.014)$. Among the men who reported daytime sleepiness while driving, there was a significant association with BQ scores, with most being classified as low rather than high risk $(22.9 \%$ versus $77.1 \% ; P=0.001)$ [Table 4].

\section{Discussion}

Sleepiness while driving is a leading cause of car crashes. ${ }^{18}$ The findings of the current study indicated that sleepiness while driving was fairly common among private car drivers in Oman, with just over onequarter of the drivers reporting that they experienced daytime sleepiness while driving at least once a month. In addition, a significantly greater proportion of male drivers experienced daytime sleepiness while driving compared to females. Despite this, females had ESS scores of $>10$ significantly more frequently. Therefore, young males were found to carry a higher risk of daytime sleepiness while driving compared to females, despite the latter having a greater propensity towards daytime sleepiness in general.

Multiple factors were observed to contribute to daytime sleepiness among drivers in the current study. Almost two-thirds of the sample had an inadequate nocturnal sleep duration of $<6$ hours per night, with a significant association between nocturnal sleep deprivation and daytime sleepiness while driving. A previous study found that $57.6 \%$ of Omani adolescents had fewer than 7 hours of sleep per night. ${ }^{19}$ This lack of sleep could be due to social- or work-related reasons, particularly in a society wherein most social events take place late at night. ${ }^{20}$ Earlier research from other parts of the world has indicated that nocturnal sleep deprivation is an important contributing factor to car crashes; for example, Valent et al. found that sleep deprivation and long working hours increased the risk of car crashes in Italy. ${ }^{21}$ Philip et al. reported that sleep deprivation negatively affected the vigilance and concentration necessary for safe driving under both real-life and simulated conditions. ${ }^{22}$

Almost half of the participants in the present study had an ESS score of $>10$, indicative of a greater propensity towards daytime sleepiness. There was also a significant association between sleepiness while driving and ESS score. These findings suggest that this scale could potentially be used as a screening tool to assess daytime sleepiness among driving licence aspirants. A study from the UK found that self-reported excessive daytime sleepiness was common among bus drivers, with $20 \%$ reporting an ESS score of $>10$ and $8 \%$ admitting that they had fallen asleep at the wheel within the previous month. ${ }^{23}$ In a similar study, Anund et al. found that 19\% of bus drivers in Sweden experienced severe sleepiness, to the point that the affected individual had to fight to stay awake while driving at least two or three times per week. ${ }^{24}$

The BQ is a useful tool to screen for OSAS and has been used in previous epidemiological research targeting the Omani population. ${ }^{20}$ Young et al. previously demonstrated that individuals with OSAS are at greater risk of having car crashes due to the symptoms of daytime sleepiness associated with the disorder. ${ }^{25}$ In the present study, there was a significant association between being at high risk of OSAS, according to BQ score, and sleepiness while driving; however, the actual number of subjects who were at risk of OSAS was relatively low. This could be explained by the fact that the studied population was relatively young and most were not overweight, as both of these factors (i.e. older age and high BMI) are associated with OSAS. ${ }^{26}$ Nevertheless, the prevalence of OSAS in this sample was $10.6 \%$, which is within the range reported by previous research (9-24\%). ${ }^{25}$ 
This study was subject to certain limitations, particularly as the findings were based solely on selfreported data. Future research should be performed in which the drivers are asked to maintain sleep and driving diaries to report their level of sleepiness every day. Such an investigation could also include objective measures such as the duration, approximate temperature and time of day or night during which each drive takes place. Additionally, this study did not precisely quantify the frequency of daytime sleepiness among the studied drivers and relied on general questions regarding the drivers' perceptions of their average level of sleepiness while driving over the previous month. Further studies should be conducted including objective measures of daytime sleepiness, such as multiple sleep latency or maintenance of wakefulness tests. Nocturnal sleep duration should also be measured more precisely via actigraphy. Finally, instead of relying on BQ responses, participants could undergo polysomnography in order to determine OSAS risk.

\section{Conclusion}

This study revealed that daytime sleepiness was fairly common among young Omani drivers. Various characteristics were found to be associated with daytime sleepiness while driving, including gender, BMI category, nocturnal sleep deprivation and snoring. These relationships should be explored further using psychometric tests.

\section{CONFLICT OF INTEREST}

The authors declare no conflicts of interest.

\section{FUNDING}

No funding was received for this study.

\section{References}

1. Akerstedt T, Fredlund P, Gillberg M, Jansson B. A prospective study of fatal occupational accidents: Relationship to sleeping difficulties and occupational factors. J Sleep Res 2002; 11:69-71. doi: 10.1046/j.1365-2869.2002.00287.x.

2. Findley LJ, Suratt PM, Dinges DF. Time-on-task decrements in "steer clear" performance of patients with sleep apnea and narcolepsy. Sleep 1999; 22:804-9. doi: 10.1093/sleep/22.6.804.

3. Engleman HM, Hirst WS, Douglas NJ. Under reporting of sleepiness and driving impairment in patients with sleep apnoea/ hypopnoea syndrome. J Sleep Res 1997; 6:272-5. doi: 10.1111/j. 1365-2869.1997.00272.x

4. Dembe AE, Erickson JB, Delbos RG, Banks SM. The impact of overtime and long work hours on occupational injuries and illnesses: New evidence from the United States. Occup Environ Med 2005; 62:588-97. doi: 10.1136/oem.2004.016667.

5. Horne J, Reyner L. Vehicle accidents related to sleep: A review. Occup Environ Med 1999; 56:289-94. doi: 10.1136/oem.56.5.289.
6. Vorona RD, Szklo-Coxe M, Lamichhane R, Ware JC, McNallen A, Leszczyszyn D. Adolescent crash rates and school start times in two central Virginia counties, 2009-2011: A follow-up study to a southeastern Virginia study, 2007-2008. J Clin Sleep Med 2014; 10:1169-77. doi: 10.5664/jcsm.4192.

7. Calhoun SL, Vgontzas AN, Fernandez-Mendoza J, Mayes SD, Tsaoussoglou M, Basta M, et al. Prevalence and risk factors of excessive daytime sleepiness in a community sample of young children: The role of obesity, asthma, anxiety/depression, and sleep. Sleep 2011; 34:503-7. doi: 10.1093/sleep/34.4.503.

8. Terán-Santos J, Jiménez-Gómez A, Cordero-Guevara J. The association between sleep apnea and the risk of traffic accidents: Cooperative Group Burgos-Santander. N Engl J Med 1999; 340:847-51. doi: 10.1056/NEJM199903183401104.

9. Young T, Blustein J, Finn L, Palta M. Sleep-disordered breathing and motor vehicle accidents in a population-based sample of employed adults. Sleep 1997; 20:608-13. doi: 10.1093/sleep/20. 8.608

10. Al-Maniri AA, Al-Reesi H, Al-Zakwani I, Nasrullah M. Road traffic fatalities in Oman from 1995 to 2009: Evidence from police reports. Int J Prev Med 2013; 4:656-63.

11. Al-Reesi H, Ganguly SS, Al-Adawi S, Laflamme L, Hasselberg M, Al-Maniri A. Economic growth, motorization, and road traffic injuries in the Sultanate of Oman, 1985-2009. Traffic Inj Prev 2013; 14:322-8 doi: 10.1080/15389588.2012.694088.

12. Ohayon MM. From wakefulness to excessive sleepiness: What we know and still need to know. Sleep Med Rev 2008; 12:129-41. doi: 10.1016/j.smrv.2008.01.001.

13. Johns MW. A new method for measuring daytime sleepiness: The Epworth sleepiness scale. Sleep 1991; 14:540-5. doi: 10.10 93/sleep/14.6.540.

14. Al-Abri M, Al-Hamhami A, Al-Nabhani H, Al-Zakwani I. Validation of the Arabic version of the Epworth Sleepiness Scale in Oman. Oman Med J 2013; 28:454-6. doi: 10.5001/omj. 2013.126.

15. Netzer NC, Stoohs RA, Netzer CM, Clark K, Strohl KP. Using the Berlin Questionnaire to identify patients at risk for the sleep apnea syndrome. Ann Intern Med 1999; 131:485-91. doi: 10.7326/0003-4819-131-7-199910050-00002

16. Saleh AB, Ahmad MA, Awadalla NJ. Development of Arabic version of Berlin questionnaire to identify obstructive sleep apnea at risk patients. Ann Thorac Med 2011; 6:212-16. doi: $10.4103 / 1817-1737.84775$.

17. Hirshkowitz M, Whiton K, Albert SM, Alessi C, Bruni O, DonCarlos L, et al. National Sleep Foundation's updated sleep duration recommendations: Final report. Sleep Health 2015; 1:233-43. doi: 10.1016/j.sleh.2015.10.004.

18. Filtness AJ, Armstrong KA, Watson A, Smith SS. Sleep-related crash characteristics: Implications for applying a fatigue definition to crash reports. Accid Anal Prev 2017; 99:440-4. doi: 10. 1016/j.aap.2015.11.024

19. Kilani H, Al-Hazzaa H, Waly MI, Musaiger A. Lifestyle habits: Diet, physical activity and sleep duration among Omani adolescents. Sultan Qaboos Univ Med J 2013; 13:510-19.

20. Al-Abri MA, Jaju D, Al-Sinani S, Al-Mamari A, Albarwani S, Al-Resadi K, et al. Habitual sleep deprivation is associated with type 2 diabetes: A case-control study. Oman Med J 2016; 31:399-403. doi: 10.5001/omj.2016.81.

21. Valent F, Di Bartolomeo S, Marchetti R, Sbrojavacca R, Barbone F. A case-crossover study of sleep and work hours and the risk of road traffic accidents. Sleep 2010; 33:349-54. doi: 10.1093/ sleep/33.3.349.

22. Philip P, Sagaspe P, Taillard J, Valtat C, Moore N, Akerstedt T, et al. Fatigue, sleepiness, and performance in simulated versus real driving conditions. Sleep 2005; 28:1511-16. doi: 10.1093/ sleep/28.12.1511. 
23. Vennelle M, Engleman HM, Douglas NJ. Sleepiness and sleeprelated accidents in commercial bus drivers. Sleep Breath 2010; 14:39-42. doi: 10.1007/s11325-009-0277-z.

24. Anund A, Ihlström J, Fors C, Kecklund G, Filtness A. Factors associated with self-reported driver sleepiness and incidents in city bus drivers. Ind Health 2016; 54:337-46. doi: 10.2486/ indhealth.2015-0217.
25. Young T, Palta M, Dempsey J, Skatrud J, Weber S, Badr S The occurrence of sleep-disordered breathing among middleaged adults. N Engl J Med 1993; 328:1230-5. doi: 10.1056/ NEJM199304293281704.

26. Deng X, Gu W, Li Y, Liu M, Li Y, Gao X. Age-group-specific associations between the severity of obstructive sleep apnea and relevant risk factors in male and female patients. PLoS One 2014; 9:e107380. doi: 10.1371/journal.pone.0107380. 